\title{
Preset ureter catheter in laparoscopic radical hysterectomy of cervical cancer
}

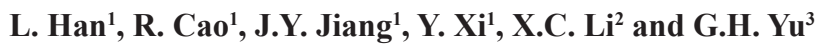 \\ 'Department of Gynecology, Dalian Obstetrics and Gynecology Hospital, \\ Dalian, China \\ ${ }^{2}$ Department of Urology, \\ The First Affiliated Hospital of Dalian Medical University, Dalian, China \\ ${ }^{3}$ Department of Urology, Dalian Municipal Central Hospital, Dalian, China \\ Corresponding author: L. Han \\ E-mail: hlxycn@yeah.net
}

Genet. Mol. Res. 13 (2): 3638-3645 (2014)

Received May 21, 2013

Accepted October 3, 2013

Published May 9, 2014

DOI http://dx.doi.org/10.4238/2014.May.9.6

ABSTRACT. The aim of this study was to evaluate the clinical
efficacy of a temporary ureteral catheter in preventing iatrogenic
ureteral damage in cervical cancer patients undergoing laparoscopic
radical hysterectomy. All cases had confirmed diagnoses of cervical
cancer preoperatively between December 2008 and December 2012
in our hospital and were in clinical stages IA2 to IIA. In total, 176
laparoscopic radical hysterectomy and lymphadenectomy procedures
were performed. The 176 cases were divided into two groups: ureteral
catheters were installed using cystoscopy before the operation in
86 patients (group A), and ureteral catheters were not placed in 90
patients (group B). These cases were retrospectively analyzed based on
postoperative hospitalization time and intraoperative and postoperative
complications. A total of 6 cases (3.41\%) had ureteral injuries, and 4
of the cases (4.65\%) of ureteral injuries occurred in group A. In two of
these cases, urinary leaking appeared at the post-operative 8 th and 9 th
days and at the 10 th and 25 th days, respectively. There were 2 cases
(2.22\%) of ureteral injuries in group B: 1 case of intraoperative direct 
injury and the other of urinary leaking, which appeared at post-operative day 21. Statistically significant differences between the two groups were observed in operating time and the incidence of hemorrhage, hematuria (including microscopic hematuria), post-operative urinary tract infection, and pain $(\mathrm{P}<0.05)$. A ureteral catheter that is placed preoperatively can help to identify the ureter in laparoscopic radical hysterectomy, but does not decrease the incidence of ureteral injury.

Key words: Ureteral catheter; Gynecological laparoscopic operation; Cervical cancer

\section{INTRODUCTION}

Radical hysterectomy is the main therapeutic approach for treating cervical cancer, and classical approaches include abdominal and vaginal operations. In recent years, with progress in equipment, apparatuses, and laparoscopy techniques, laparoscopy operations have shown advantages of little trauma, less bleeding, and quicker post-operative recovery. Therefore, laparoscopy radical hysterectomy has become the preferred operation type for treating early-stage cervical cancer (Campos et al., 2009; Lee et al., 2010). Most doctors who can perform radical hysterectomies have experience in celiotomies and basic laparoscopic operations for benign gynecological diseases. Nevertheless, because of the insufficient understanding of the anatomical structure surrounding the cervix under the microscope, unskillful handling, and the use of electric energy devices, urinary system injury complications can easily occur in the early stage of performing this type of operation, with ureteral injury being one of the most serious complications. As laparoscopic hysterectomy and retroperitoneal operations, such as pelvic lymph node dissections, have increasingly been adopted, the occurrence rate of laparoscopic ureteral injury has also increased (Cholkeri-Singh et al., 2007; Tanaka et al., 2008). Furthermore, the rate of ureteral injuries resulting from laparoscopic operations is substantially higher than that resulting from celiotomies (Uccella et al., 2007; Chong et al., 2009). Ureteral injury results in not only increased medical expenses, but also increased physical and emotional damage for patients. Therefore, great precaution should be taken to avoid the occurrence of ureteral injury.

Some researchers have suggested that a ureteral catheter should be placed as a precaution before the operation in order to prevent the occurrence of ureteral injury in gynecological laparoscopic operations (Koh et al., 2004; Quinlan et al., 2009); however, some researchers have suggested that injuries and urinary complications can easily occur with the use of such catheters (Wood et al., 1996; Kuno et al., 1998). Whether or not this is relevant to laparoscopic radical hysterectomies has not yet been reported. This study evaluated the value of presetting a ureteral catheter prior to performing a laparoscopic radical hysterectomy.

\section{MATERIAL AND METHODS}

\section{Patients}

This study was conducted in accordance with the declaration of Helsinki and with 
approval from the Ethics Committee of the Dalian Obstetrics and Gynecology Hospital. Written informed consent was obtained from all participants. Cervical cancer was diagnosed between December 2008 and December 2012, and the clinical stage of all patients ranged from stages IA2 to IIA. Laparoscopic radical hysterectomy and retroperitoneal lymph node dissection were applied to a total of 176 cases who ranged in age from 16-72 years, with an average age of 44.52 \pm 23.48 years. The patients were randomly divided into two groups, $\mathrm{A}$ and $\mathrm{B}$, depending on the use of a ureteral catheter: 86 cases had a ureteral catheter set before the operation (group A) and 90 cases did not have a ureteral catheter set before the operation (group B). Groups were established according to the International Federation of Gynecology and Obstetrics (FIGO) clinical dividing group criterion of 2000. Group A comprised 10 cases at stage IA2, 54 cases at stage IB1, 11 cases at stage IB2, 11 cases at stage IIA, 75 cases of squamous cell carcinoma, 8 cases of adenocarcinoma, and 3 cases of adenosquamous carcinoma. Group B comprised 6 cases at stage IA2, 61 cases at stage IB1, 14 cases at stage IB2, 9 cases at stage IIA, 78 cases of squamous cell carcinoma, 9 cases of adenocarcinoma, and 3 cases of adenosquamous carcinoma. The operative method was laparoscopic radical hysterectomy and pelvic lymph node dissection, among which 75 cases $(42.61 \%)$ had para-aortic lymphadenectomies performed at the same time. The two groups did not differ in terms of age, tumor staging, histological type, or operation methods.

\section{Setting of the ureteral catheter}

The patient's urinary bladder was placed in the lithotomy position and $2 \%$ lidocaine topical anesthesia was applied. A number F21 cystoscope was inserted in the bladder, finding each side of the ureteral orifice, and a number F4 ureteral catheter was inserted. After the catheter was successfully set, it was indwelled and fixed. The ureteral catheter was extracted 7 days after the operation.

\section{Radical hysterectomy and lymph node dissection}

Retroperitoneal iliac vessels were exposed, gradually eradicating the iliac general tissue, inguinal deep tissue, obturator tissue, obturator fossa tissue, internal iliac tissue, and other lymph nodes and adipose tissues from the proximal to the distal end. In a portion of the cases, the superior mesenteric arterial level para-aortic lymph nodes and adipose tissue were also eradicated.

The pelvic funnel ligaments were cut at the pelvic ingress, the proximal portion of the uterine artery was cut, the bladder was sheared and peritoneal folds reversed, and the rectal peritoneal folds were reversed to separate the gap between the bladder and the cervix and the coleorectal space and the rectal lateral fossa, and the sacral ligament was cut $3 \mathrm{~cm}$ from the cervix. The bladder cervix ligaments were gradually cut pre and post lobes by use of an ultrasonic scalpel. The bladder areola was opened, the cardinal ligaments were cut, the paracolpium was cut $3 \mathrm{~cm}$ from the cervix, the vagina was ring-cut $3 \mathrm{~cm}$ from the cervix, and finally, the uterus and all groups of lymph nodes were removed and the vaginal section was sutured.

\section{Post-operative management}

Patients were given two-suite antibiotics for 3-5 days to prevent infection. Patients received conventional indwelling catheterization for 14 days after the operation, urinary cath- 
eters were opened in a timely manner, and dysuria or a residual urine volume $>100 \mathrm{~mL}$ after the extraction of the urinary catheter was regarded as retention of urine and a continually indwelling catheter. Mid-stream urine culture bacterial counts $>10^{5} / \mathrm{mL}$ or a routine urinalysis leukocyte count $>3-5$ Helicobacter pylori indicated urinary tract infection.

\section{Statistical analysis}

The SPSS13.0 software was used for statistical analyses. Measurement data were evaluated using the Student $t$-test, and enumeration data were evaluated with the $\chi^{2}$ test. $\mathrm{P}<$ 0.05 indicated statistical significance.

\section{RESULTS}

\section{Injury occurrence and duration during the operation}

Significant differences in terms of operation time and intraoperative blood loss were observed between the patients who received ureteral catheter settings (group A) and those who did not (group $\mathrm{B})(\mathrm{P}<0.05)$. There was one case of ureteral injury during the operation in group B (Table 1).

Table 1. Comparative situations of two groups of patients during operation.
\begin{tabular}{|ccccc}
\hline Group & Case No. & Ureteral injury (\%) & Operation time (min) & Bleeding during operation (mL) \\
\hline A & 56 & 0 & $206.23 \pm 34.56 *$ & $208.67 \pm 148.89^{*}$ \\
B & 46 & $1(2.17)$ & $246.57 \pm 37.81$ & $256.13 \pm 176.65$ \\
\hline$* \mathrm{P}<0.05 v s$ B group. & & &
\end{tabular}

\section{Post-operative complications}

The incidence rates of post-operative hematuria and post-operative pain differed significantly between groups $\mathrm{A}$ and $\mathrm{B}(\mathrm{P}<0.05)$.

There were 4 cases with urine leakage in the ureteral catheter setting group (group A) and there was one case with urine leakage in the ureteral catheter unsetting group (group B) (Table 2).

Table 2. Comparison of post-operative complications of two groups of patients.
\begin{tabular}{|cccccc}
\hline Group & Case No. & Ureteral injury (\%) & Hematuria (\%) & Urinary tract infection (\%) & Pain (\%) \\
\hline A & 56 & $2(3.57)$ & $48(85.71)^{*}$ & $17(26.15)^{*}$ & $45(80.35)^{*}$ \\
B & 46 & $1(2.17)$ & $6(13.04)$ & $5(15.15)$ & 0 \\
\hline
\end{tabular}

*P $>0.05$ vs $\mathrm{B}$ group.

\section{Ureteral injury}

Overall, there were 6 cases (3.41\%) with ureteral injury. Four of the injury cases $(4.65 \%)$ were in the ureteral catheter setting group, which first occurred in the vaginal fluid, $8,9,10$, and 
25 days after the operation, respectively, and then gradually increased. Injuries were diagnosed as uretero-vaginal fistula through determinations of vaginal fluid urea, and were treated with intravenous pyelography; after computed tomography examinations, double ' J' tubes drainage operations were performed through bladder and ureteral bladder implantation. Two cases of injury occurred in the non-ureteral catheter setting group (2.22\%). In one case, the urinary catheter was directly divided outside of the sacral ligament because the trend of the catheter was not clear; the ureteral terminal anastomosis was immediately treated and double ' $J$ ' tubes were set when the trend was identified during the operation. Injury in the other case was found 21 days after the operation, and was treated by lateral ureteral bladder implantation (Table 3).

\begin{tabular}{|c|c|c|c|c|c|c|c|}
\hline Patient & Preoperative diagnosis & $\begin{array}{l}\text { Ureteral } \\
\text { catheter }\end{array}$ & $\begin{array}{l}\text { Discovery } \\
\text { time }\end{array}$ & Injury pathway & Injuries portion & Injuries treatment & Prognosis \\
\hline 1 & $\begin{array}{l}\text { Cervical } \\
\text { adenocarcinoma-b1 stage }\end{array}$ & No & $\begin{array}{l}\text { During } \\
\text { operation }\end{array}$ & $\begin{array}{l}\text { Injuries during } \\
\text { operation }\end{array}$ & Left lower ureter & $\begin{array}{l}\text { Anastomosis of left ureteral } \\
\text { catheter, double ' } \mathrm{J} \text { ' tube }\end{array}$ & Good \\
\hline 2 & $\begin{array}{l}\text { Squamous carcinoma } \\
\text { of the cervix-b1stage }\end{array}$ & Yes & $\begin{array}{l}9 \text { days after } \\
\text { operation }\end{array}$ & $\begin{array}{l}\text { Uretero-vaginal } \\
\text { fistula }\end{array}$ & $\begin{array}{l}\text { Lower end of two-sides } \\
\text { ureteral catheter }\end{array}$ & $\begin{array}{l}\text { Setting double 'J' tubes drainage } \\
\text { through the two sides of bladder }\end{array}$ & Good \\
\hline 3 & $\begin{array}{l}\text { Squamous carcinoma } \\
\text { of the cervix-a stage }\end{array}$ & Yes & $\begin{array}{l}25 \text { days after } \\
\text { operation }\end{array}$ & $\begin{array}{l}\text { Uretero-vaginal } \\
\text { fistula }\end{array}$ & $\begin{array}{l}\text { Lower end of right } \\
\text { ureteral catheter }\end{array}$ & $\begin{array}{l}\text { Bladder implantation of right } \\
\text { ureteral catheter }\end{array}$ & Good \\
\hline 4 & $\begin{array}{l}\text { Squamous carcinoma } \\
\text { of the cervix-b1stage }\end{array}$ & No & $\begin{array}{l}21 \text { days after } \\
\text { operation }\end{array}$ & $\begin{array}{l}\text { Uretero-vaginal } \\
\text { fistula }\end{array}$ & $\begin{array}{l}\text { Left ureteral catheter near } \\
\text { the entrance of bladder }\end{array}$ & $\begin{array}{l}\text { Bladder implantation of left } \\
\text { ureteral catheter }\end{array}$ & Good \\
\hline
\end{tabular}

\section{DISCUSSION}

The application of laparoscopic operations shows an increasing trend in gynecological practice; however, ureteral injury is a potentially severe complication of pelvic laparoscopic operations. In open surgery, as the difficulties of operations increase, the probability of ureteral injury increases by $0-2.0 \%$ (Uccella et al., 2007; Chong et al., 2009), whereas the probability of ureteral injury in laparoscopic operations increases by $0.2-6.0 \%$ (Cholkeri-Singh et al., 2007; Tanaka et al., 2008). This increased risk is due to the limitations of visual exposure, the lack of touch, and the use of an energy apparatus. Furthermore, laparoscopic radical hysterectomy requires opening the ureteral tunnel, which also increases the chances of ureteral injury and other severe complications.

Park et al. (2002) reported that in 52 patients with stage IB1 cervical cancer treated with laparoscopic radical hysterectomy and pelvic lymph node dissection, there were 2 cases of ureteral injury (3.8\%). Xu et al. (2007) reported 5 cases of ureteral injury among 317 cases $(1.58 \%)$ of laparoscopic radical hysterectomy and pelvic lymph node dissection. Lee et al. (2010) reported that of 139 cases of cervical cancer that were treated with laparoscopic radical hysterectomy and pelvic lymph node dissection, only one case $(0.72 \%)$ showed ureteral injury.

In order to prevent ureteral injury in laparoscopic radical hysterectomies, we treated 86 cases with ureteral catheter setting before operations, did not place ureteral catheters in 90 cases, and differences between these two groups were evaluated with respect to the occurrence of injury, operation time, amount of bleeding, and associated complications.

There were 4 cases $(4.65 \%)$ with ureteral injury in the ureteral catheter-setting group and 2 cases $(2.22 \%)$ with ureteral injury in the non-ureteral catheter-setting group. Therefore, setting a ureteral catheter did not prevent the incidence of ureteral injury. Reviewing and ana- 
lyzing the operation videos of ureteral catheter setting showed that the injuries in this group all occurred within $5 \mathrm{~cm}$ of the bladder entrance in the lower ureter; therefore, injuries caused by operation mistakes when dealing with ureter tunnels should be taken into consideration. The anatomy of the ureter tunnel, which was the location of the ureteral catheter, is clear and is easy to discern and separate. Furthermore, the flexibility of the ureteral catheter was found to decrease in the tunnel, and if its peristalsis goes off, thermal injury is likely because of the ureteral catheter drifting away. The opportunity of timely setting double ' $\mathrm{J}$ ' tubes in highly suspected injury patients is lost in cases of thermally injured ureteral catheters. This is either because of the inability to notice local motility or because of the presence of abnormal thickening or injuries that were not caused by setting the ureteral catheter. There were two cases of ureteral injury that occurred in the early stage of the operation, which were likely due to undeveloped technique. However, after setting the ureteral catheter, it is easier to discern the anatomical relationship between the catheter and its surrounding tissues, either by visual inspection or by touching the apparatus, which can prevent direct injuries during the operation, especially when dealing with common iliac lymph nodes, and the separation of the rectum fossa, ureter tunnel entrance, and uterine arterial intersections. In the non-ureteral cathetersetting group, there was one case of direct injury because the trend was not clear during the operation and the ureteral catheter was directly cut outside of the sacral ligament; in the ureteral catheter-setting group, such case has not been found. Another case of injury in the nonureteral catheter-setting group occurred when dealing with the left bladder cervical ligament anterior lobes, which were bleeding followed by bipolar coagulation hemostasis because of unclear local anatomy. In this case, thermal injuries could not be avoided although local heat was decreased by flushing while setting.

In this study, the operation time of the ureteral catheter-setting group was shorter than that of the non-ureteral catheter-setting group, and the volume of bleeding was lower in the ureteral catheter-setting group. These factors are significant when beginners preset temporary ureteral catheters before laparoscopic radical hysterectomy. This study also found that the occurrence rates of post-operative hematuria (including microscopic hematuria), post-operative urinary tract infections, and other associated complications were higher in the ureteral catheter setting group; however, there was no case of direct injury to the ureter, urine reflux, or other complications caused by setting the catheter.

Previous studies have advocated preventively setting a ureteral catheter (Basiri et al., 2007; Rassweiler et al., 2007; Siow et al., 2007) before laparoscopic gynecological pelvic surgery; however, some authors have expressed opposing opinions worrying that catheters might cause injuries and post-operative complications of the urinary system (Bothwell et al., 1994; Wood et al., 1996; Kuno et al., 1998). Quinlan et al. (2009) found that the use of a ureteral catheter could increase discrimination in complicated pelvic surgery, thus diminishing injury through negligence. Tanaka et al. (2008) showed that preventively setting a ureteral catheter was beneficial for discerning the ureter, and could prevent ureteral injuries in laparoscopic hysterectomy; it could also spontaneously heal mild injuries of the ureter through prolonged intubation. In contrast, Kuno et al. (1998) showed that indiscriminately applying a temporary ureteral catheter in gynecological surgery was not helpful for preventing ureteral injury. Other studies (Wood et al., 1996) showed that the routine use of ureteral catheters might cause unnecessary complications. Setting a ureteral catheter could not only increase the urinary tract infection rate, but might also cause urine return, hematuria, fever, and other complications. 
Many studies related to laparoscopic gynecological operations, such as laparoscopic radical hysterectomy and laparoscopic endometriosis, have shown that presetting a ureteral catheter before the operation can prevent the occurrence of ureteral injuries and improve the safety of the operation. This type of operation does not need to deal with the ureteral tunnel, it simply requires discerning of the ureteral catheter and opening the ureter. Although in laparoscopic radical hysterectomies, the ureteral catheter must be set in the ureteral tunnel, whether presetting the ureteral catheter before this kind of operation might prevent ureteral injuries awaits further research with a large quantity of clinical data.

Laparoscopic radical hysterectomy has been routinely used to treat early-stage cervical cancer (Campos et al., 2009; Lee et al., 2010). Laparoscopic examination provides valuable information for treating anterior local later-stage cervical cancer (Leblanc et al., 2007). Compared with benign lesion hysterectomy, the ureteral injury rate of laparoscopic radical hysterectomy is usually higher, with laparoscopy being one of the hazards (Forsgren et al., 2010; Frankman et al., 2010). The results of this study suggested that presetting a ureteral catheter before laparoscopic radical hysterectomy is beneficial for discerning the ureter during the operation, but this procedure does not decrease the occurrence rate of ureteral injury. Those performing laparoscopic radical hysterectomies must have intimate knowledge of normal trends and easily injured parts of the ureter. For example, petechia should be identified during the operation, bleeding should be carefully stopped, clamping tissues and electric coagulation homeostasis should not be excessively used, the dissection of the lower end of the ureteral catheter should be minimized, and ureteral necrosis should be avoided. The most important factors for avoiding ureteral injury are skilled operation skills and enriched experience of the surgeon; therefore, systemic training is beneficial to reduce the learning curve (Lim et al., 2010).

\section{REFERENCES}

Basiri A, Mohammad Ali BF, Abdi H and Mahmoudnejad N (2007). Laparoscopic reimplantation for single-system ectopic ureter. Urol. J. 4: 174-176.

Bothwell WN, Bleicher RJ and Dent TL (1994). Prophylactic ureteral catheterization in colon surgery. A five-year review. Dis. Colon Rectum 37: 330-334.

Campos LS, Limberger LF, Kalil AN, de Vargas GS, et al. (2009). Videolaparoscopic radical hysterectomy approach: a ten-year experience. JSLS 13: 504-508.

Cholkeri-Singh A, Narepalem N and Miller CE (2007). Laparoscopic ureteral injury and repair: case reviews and clinical update. J. Minim. Invasive Gynecol. 14: 356-361.

Chong GO, Park NY, Hong DG, Cho YL, et al. (2009). Learning curve of laparoscopic radical hysterectomy with pelvic and/or para-aortic lymphadenectomy in the early and locally advanced cervical cancer: comparison of the first 50 and second 50 cases. Int. J. Gynecol. Cancer 19: 1459-1464.

Forsgren C and Altman D (2010). Risk of pelvic organ fistula in patients undergoing hysterectomy. Curr. Opin. Obstet. Gynecol. 22: 404-407.

Frankman EA, Wang L, Bunker CH and Lowder JL (2010). Lower urinary tract injury in women in the United States, 1979-2006. Am. J. Obstet. Gynecol. 202: 495.

Koh LW, Koh PH, Lin LC, Ng WJ, et al. (2004). A simple procedure for the prevention of ureteral injury in laparoscopicassisted vaginal hysterectomy. J. Am. Assoc. Gynecol. Laparosc. 11: 167-169.

Kuno K, Menzin A, Kauder HH, Sison C, et al. (1998). Prophylactic ureteral catheterization in gynecologic surgery. Urology 52: 1004-1008.

Leblanc E, Narducci F, Frumovitz M, Lesoin A, et al. (2007). Therapeutic value of pretherapeutic extraperitoneal laparoscopic staging of locally advanced cervical carcinoma. Gynecol. Oncol. 105: 304-311.

Lee CL, Wu KY, Huang KG, Lee PS, et al. (2010). Long-term survival outcomes of laparoscopically assisted radical hysterectomy in treating early-stage cervical cancer. Am. J. Obstet. Gynecol. 203: 165-167. 
Lim MC, Lee BY, Lee DO, Joung JY, et al. (2010). Lower urinary tract injuries diagnosed after hysterectomy: seven-year experience at a cancer hospital. J. Obstet. Gynaecol. Res. 36: 318-325.

Park CT, Lim KT, Chung HW, Lee KH, et al. (2002). Clinical evaluation of laparoscopic-assisted radical vaginal hysterectomy with pelvic and/or paraaortic lymphadenectomy. J. Am. Assoc. Gynecol. Laparosc. 9: 49-53.

Quinlan DJ, Townsend DE and Johnson GH (2009). Are ureteral catheters in gynecoiogic beneficial or hazardous. J. AM. Assoc. Gynecol. Laparosc. 3: 61.

Rassweiler JJ, Gozen AS, Erdogru T, Sugiono M, et al. (2007). Ureteral reimplantation for management of ureteral strictures: a retrospective comparison of laparoscopic and open techniques. Eur. Urol. 51: 512-522.

Siow A, Nikam YA, Ng C and Su MC (2007). Urological complications of laparoscopic hysterectomy: a four-year review at KK Women's and Children's Hospital, Singapore. Singapore Med. J. 48: 217-221.

Tanaka Y, Asada H, Kuji N and Yoshimura Y (2008). Ureteral catheter placement for prevention of ureteral injury during laparoscopic hysterectomy. J. Obstet. Gynaecol. Res. 34: 67-72.

Uccella S, Laterza R, Ciravolo G, Volpi E, et al. (2007). A comparison of urinary complications following total laparoscopic radical hysterectomy and laparoscopic pelvic lymphadenectomy to open abdominal surgery. Gynecol. Oncol. 107: S147-S149.

Wood EC, Maher P and Pelosi MA (1996). Routine use of ureteric catheters at laparoscopic hysterectomy may cause unnecessary complications. J. Am. Assoc. Gynecol. Laparosc. 3: 393-397.

Xu H, Chen Y, Li Y, Zhang Q, et al. (2007). Complications of laparoscopic radical hysterectomy and lymphadenectomy for invasive cervical cancer: experience based on 317 procedures. Surg. Endosc. 21: 960-964. 